\title{
Analisis Efisiensi Penggunaan Faktor Produksi Usahatani Cabai Merah di Desa Besakih, Kecamatan Rendang, Kabupaten Karangasem
}

\author{
NI WAYAN ADIYANI WIJAYANTI, RATNA KOMALA DEWI, \\ I WAYAN WIDIYANTARA \\ Program Studi Agribisnis Fakultas Pertanian Universitas Udayana \\ Jl. PB. Sudirman Denpasar 80232 \\ Email: adiyaniwijayanti15@yahoo.co.id \\ ratnadewi61@ymail.com
}

\author{
Abstract \\ Efficiency Analysis of The Use Of Red Chili Production Factors \\ in Red Chili Farming at Besakih Village, Rendang, Karangasem
}

The research was conducted in Besakih Village, Rendang Sub-District, Karangasem Regency which is one of red chili farming centers in Karangasem Regency. The problem is that production tends to decline over the past five years. This study aims to analyze the effect of production factors and the level of efficiency of the use of red chili production factors on the red chili production in Besakih Village. The method used to analyze the factors of production was the Cobb-Douglas production function. Data were obtained from 62 respondents by census method. Efficiency was calculated by analyzing the ratio of marginal production prices to factor prices. The results showed that production factors that affect the amount of production include land, seed, manure, NPK, leaf fertilizer, calcium fertilizer, pesticides, and labor. Simultaneously, the influence of production factor was $93,90 \%$ to the amount of red chili production, while partially, factors that affect the production of red chili were seed, manure, NPK and pesticide. The production factor that has been efficient in its use was NPK fertilizer. Factors of seed production and manure have not been efficient, so their use needs to be added. Leaf fertilizer production factors, calcium fertilizers, pesticides, and labor usage were inefficient, so the use needs to be reduced.

Keywords: red chili, production factors, cobb-douglas, efficiency

\section{Pendahuluan}

\subsection{Latar Belakang}

Salah satu tujuan pembangunan sektor pertanian di Indonesia adalah meningkatkan pendapatan petani dengan mengembangkan sistem usaha tani yang berwawasan agribisnis agar mampu menghasilkan produk yang berkualitas, berproduktivitas tinggi dan efisien. Subsektor hortikultura merupakan salah satu 
subsektor pertanian yang memiliki potensi yang cukup besar karena didukung oleh payung hukum/regulasi, keanekaragaman hayati, ketersediaan lahan pertanian, agroklimat (iklim yang sesuai), dukungan teknologi, ketersedian tenaga kerja, ketersedian pasar, dukungan penetapan komoditas prioritas hortikultura, dukungan pengembangan sistem perbenihan hortikultura dan dukungan pengembangan sistem perlindungan hortikultura (Dirjen Hortikultura, 2015).

Tanaman hortikultura terdiri atas kelompok tanaman sayuran (vegetables), buah (fruits), tanaman berkhasiat obat (medicinal plants), tanaman hias (ornamental plants) termasuk didalamnya tanaman air, dan jamur yang dapat berfungsi sebagai sayuran, tanaman obat atau tanaman hias. Adapun komoditas hortikultura yang akan secara intensif mendapat perhatian utama pada level nasional pada periode 2015 sampai 2019 adalah aneka cabai, bawang merah, jeruk (Dirjen Hortikultura, 2015).

Menurut Saptana et al. (2010), beberapa alasan penting pengembangan komoditas cabai merah besar, antara lain adalah (1) tergolong sebagai komoditas bernilai ekonomi tinggi, (2) merupakan salah satu komoditas sayuran unggulan nasional, (3) menduduki posisi penting dalam hampir seluruh menu masakan diIndonesia, (4) memiliki prospek ekspor yang baik, (5) mempunyai daya adaptasi yang luas, dan (6) bersifat intensif dalam menyerap tenaga kerja.

Salah satu propinsi penghasil cabai adalah Propinsi Bali. Dapat diketahui selama tiga tahun terakhir produksi holtikultura sayur-sayuran di dominasi oleh komoditi cabai. Tahun 2013 produksi cabai di Bali mencapai 35.856 ton atau sebesar $21.43 \%$ dari total produksi sayur, di tahun 2014 produksi cabai meningkat menjadi 48.788 ton atau sekitar 23,89\% dan tahun 2015 produksi cabai mencapai 45.386 ton atau sebesar 25,78 \% (Badan Pusat Statistik, 2016). Berikut ini adalah data produksi cabai di masing-masing kabupaten, Propinsi Bali.

Kabupaten Karangasem merupakan penghasil cabai tertinggi di Propinsi Bali (Badan Pusat Statistik, 2016). Cabai yang maksud dalam hal ini terdiri atas cabai merah, cabai keriting, dan cabai rawit. Cabai merah merupakan salah satu komoditi yang dikembangkan di wilayah Karangasem. Salah satu wilayah yang mengembangkan usahatani cabai merah di Kabupaten Karangasem adalah Kecamatan Rendang. Namun selama lima tahun terakhir produksi cabai merah cenderung mengalami penurunan. Produktivitas mengalami penurunan rata-rata 1,07 ton/ha setiap tahunnya. Penurunan produktivitas tanaman cabai merupakan salah satu permasalahan dalam menjalankan usahatani cabai yang akan berdampak pada penerimaan petani cabai.

Desa Besakih merupakan salah satu kawasan yang menggembangkan usahatani cabai merah di Kecamatan Rendang, Kabupaten Karangasem. Budidaya cabai di Desa Besakih dilakukan di lahan tegalan atau lahan perkebunan. Desa ini tidak memiliki tanah sawah namun memiliki lahan tegalan dengan luas 1.127,60 ha, yang dimanfaatkan untuk berbagai kegiatan usahatani, salah satunya adalah usahatani cabai merah (Badan Pusat Statistik, 2015). 
Penurunan produktivitas cabai merah dapat dipengaruhi beberapa faktor antara lain, faktor alam yaitu iklim, kondisi geografi, dan faktor penggunaan input produksi yang meliputi luas lahan, benih, pupuk, pestisida, dan penggunaan tenaga kerja. Faktor alam memang cukup sulit dikendalikan karena diluar kemampuan petani. Namun untuk mengelola faktor penggunaan produksi hal ini bisa dilakukan dengan mengelola penggunaan faktor produksi secara efisien karena faktor produksi memegang peranan yang sangat penting dalam melakukan usahatani. Penggunaan faktor produksi secara efisien berarti upaya penggunaan input yang sekecil-kecilnya untuk mendapatkan produksi yang sebesar-besarnya (Soekartawi, 1994), sehingga produksinya optimal. Berdasarkan uraian diatas maka peneliti tertarik untuk melakukan analisis mengenai efisiensi penggunaan faktor produksi usahatani cabai di Desa Besakih, Kecamatan Rendang, Kabupaten Karangasem.

\subsection{Tujuan Penelitian}

Penelitian ini bertujuan untuk mengetahui faktor produksi usahatani cabai merah dan pengaruhnya terhadap produksi cabai merah serta menganalisis efisiensi penggunaan faktor produksi usahatani cabai merah di Desa Besakih, Kecamatan Rendang, Kabupaten Karangasem.

\section{Metodologi Penelitian}

\subsection{Lokasi dan Waktu Penelitian}

Pemilihan lokasi penelitian ditentukan dengan metode purposive yaitu suatu teknik penentuan lokasi penelitian secara sengaja karena Desa Besakih merupakan salah satu sentra penghasil komoditi cabai merah merah dengan luas tanam terluas di Kabupaten Karangasem yang sudah memulai usahatani cabai merah sejak tahun 2004. Penelitian dimulai dari bulan Februari sampai Maret 2017.

\subsection{Populasi dan Sampel Penelitian}

Populasi dalam penelitian ini adalah petani cabai merah di Desa Besakih yang menanam cabai merah merah pada musim tanam Juli 2016 sampai dengan Januari 2017, yang berjumlah 62 orang. Penetapan sampel diambil dengan metode sensus yaitu mengambil seluruh anggota populasi sebagai sample dengan jumlah petani cabai merah (62 orang).

\subsection{Jenis dan Sumber Data}

Jenis data yang dikumpulkan dalam penelitian ini ada dua jenis yaitu data kuantitatif dan data kualitatif. Data kuantitatif pada penelitian ini antara lain data produksi cabai merah, jumlah faktor produksi, harga masing-masing faktor produksi, harga cabai merah dalam satu musim tanam. Data kualitatif yang digunakan dalam penelitian ini antara lain gambaran umum usahatani dan lingkungan di Desa Besakih. 
Sumber data berasal dari data primer dan data sekunder (Sugiyono, 2012). Data primer adalah data berupa hasil wawancara secara langsung kepada narasumber (petani) dengan menggunakan kuisioner. Data sekunder dalam hal ini diperoleh dari literatur-literatur dan instansi yang terkait seperti Badan Pusat Statistik, Kementrian Pertanian, Statistik Produksi Hortikultura, Pusdatin, Direktorat Jenderal Hortikultura, UPTD (Unit Pelaksana Teknis Daerah), media internet, buku-buku mengenai konsep usahatani, dan bahan pustaka lain yang relevan.

\subsection{Metode Pengumpulan Data dan Variabel Penelitian}

Pengumpulan data mengenai usahatani cabai merah di Desa Besakih melalui wawancara dengan berpedoman pada kuisioner. Variabel yang dianalisis adalah : (1) jumlah produksi; (2) jumlah faktor produksi yang digunakan; (3) harga produksi; dan (4) harga masing-masing faktor produksi. Seluruh variabel dianalisis dengan metode deskriptif kuantitatif untuk menganalisis efisiensi penggunaan faktor produksi usahatani cabai merah.

\subsection{Metode Analisis}

Pengukuran terhadap pengaruh faktor produksi terhadap produksi cabai merah menggunakananalisis model regresi dan uji asumsi klasik, sedangkan pengukuran terhadap efisiensi penggunaan faktor produksi menggunakan analisis fungsi produksi Cobb-Douglas dan analisis efisiensi penggunaan faktor produksi dalam usahatani. Berikut ini adalah analisis yang digunakan dalam penelitian ini.

a) Analisis model regresi digunakan untuk mengetahui kesesuaian model penduga dengan data yang digunakan dengan menggunakan program SPSS. Analisis model regresi terdiri atas uji koefisien determinasi $\left(\mathrm{R}^{2}\right)$, uji ragam regresi, dan uji koefisien determinasi.

b) Uji asumsi klasik dilakukan untuk mengetahui kelayakan suatu model pendugaan dengan metode kuadrat terkecil (Ordinary Least Square). Dalam melakukan uji asumsi klasik ini digunakan program SPSS 19. Asumsi yang harus dipenuhi dalam menggunakan metode OLS antara lain uji normalitas dan uji multikolinieritas.Uji normalitas dilakukan dengan uji Kurtosis dan Skewness. Suatu model dapat dikatakan terdistribusi normal apabila nilai rasio skewnes dan kurtosis berada diantara negatif dua dan positif dua, yaitu dengan membandingkan nilai statistik dengan standar eror (Santoso, 2002). Multikolinearitas merupakan hubungan linier yang sempurna antara variabelvariabel bebas (X) dalam metode analisis regresi (Tenaya, 2009). Uji multikolinearitas juga dapat dilihat melalui nilai VIF (Varian Inflation Factor) dan tolerance pada hasil regresi. Adanya kolinieritas ditandai dengan rendahnya nilai tolerance dengan batasan maksimum 0,1 dan nilai VIF yang tinggi dengan batasan minimum 10 .

c) Analisis fungsi produksi Cobb-Douglas digunakan untuk menduga produksi usahatani cabai merah merah di Desa Besakih yang menggunakan metode 
kuadarat terkecil atau OLS (Ordinary Least Square) dengan metode analisis fungsi produksi Cobb-Douglas sebagai berikut.

$$
\mathrm{Y}=\alpha \mathrm{X} 1^{\beta 1} \mathrm{X} 2^{\beta 2} \mathrm{X} 3^{\beta 3} \mathrm{X} 4^{\beta 4} \mathrm{X} 5^{\beta 5} \mathrm{X} 6^{\beta 6} \mathrm{X} 7^{\beta 7} \mathrm{X} 8^{\beta 8} \mathrm{e}^{\mathrm{u}}
$$

$\mathrm{Y}=$ Jumlah produksi cabai merah $(\mathrm{kg})$

$\mathrm{X}_{1} \quad=$ Luas lahan (ha)

$\mathrm{X}_{2} \quad=$ Benih $(\mathrm{gram} / \mathrm{Ha})$

$\mathrm{X}_{3} \quad=$ Pupuk kandang $(\mathrm{kg} / \mathrm{Ha})$

$\mathrm{X}_{4} \quad=$ NPK $(\mathrm{kg} / \mathrm{Ha})$

$\mathrm{X}_{5} \quad=$ Pupuk daun (liter/Ha)

$\mathrm{X}_{6} \quad=$ Kalsium $(\mathrm{kg} / \mathrm{Ha})$

$\mathrm{X}_{7} \quad=$ Pestisida $(\mathrm{l} / \mathrm{Ha})$

$\mathrm{X}_{8} \quad=$ Tenaga kerja $(\mathrm{HOK} / \mathrm{Ha})$

$\log \alpha=$ intersep regresi

$\mathrm{B}_{\mathrm{i}} \quad=$ Koefisien regresi sekaligus produksi marjinal masing-masing input ke $\mathrm{k}_{1-8}$

$\mathrm{e}^{\mathrm{u}} \quad=$ Galat (disturbance error)

Menurut Soekartawi (1994), untuk memudahkan pendugaan terhadap persamaan, maka persamaan tersebut diubah menjadi bentuk linier berganda dengan cara melogartimakan persamaan tersebut. Analisis ini menggunakan program SPSS 19. Berikut adalah bentuk matematis dari persamaan yang telah dilogaritmakan.

$$
\begin{aligned}
\log Y= & \log \alpha+\beta 1 \log X_{1}+\beta 2 \log X_{2}+\beta 3 \log X_{3}+\beta 4 \log X_{4} \\
& +\beta 5 \log X_{5} \beta 6 \log X_{6}+\beta 7 \log X_{7}+\beta 8 \log X_{8}+u \ldots \ldots \ldots
\end{aligned}
$$

Keterangan :

$\mathrm{Y}=$ Jumlah produksi cabai merah $(\mathrm{kg})$

$\mathrm{X}_{1} \quad=$ Luas lahan (ha)

$\mathrm{X}_{2}=$ Benih $(\mathrm{gram} / \mathrm{Ha})$

$\mathrm{X}_{3} \quad=$ Pupuk kandang $(\mathrm{kg} / \mathrm{Ha})$

$\mathrm{X}_{4} \quad=\mathrm{NPK}(\mathrm{kg} / \mathrm{Ha})$

$\mathrm{X}_{5} \quad=$ Pupuk daun (liter/Ha)

$\mathrm{X}_{6} \quad=$ Kalsium $(\mathrm{kg} / \mathrm{Ha})$

$\mathrm{X}_{7} \quad=$ Pestisida $($ liter $/ \mathrm{Ha})$

$\mathrm{X}_{8} \quad=$ Tenaga kerja $(\mathrm{HOK} / \mathrm{Ha})$

$\log \alpha=$ intersep regresi

$\beta_{1} \quad=$ Koefisien regresi sekaligus elastisitas produksi masing-masing input

$\mathrm{u} \quad=$ Galat (disturbance error)

d) Analisis efisiensi penggunaan faktor produksi usahatani cabai merah besar dapat dilihat dari hubungan yang terjadi antara nilai produksi marginal (NPMxi) dengan harga faktor produksi (Pxi) yang bersangkutan. Tingkat efisiensi penggunaan masing-masing faktor produksi dapat dihitung dengan rumus :

$$
\text { NPMxi }=\text { Pxi atau } \frac{\text { NPMxi }}{\text { Pxi }}=1
$$

Keterangan

NPMxi $=$ nilai produk marginal faktor produksi ke $\mathrm{i}$

Pxi = harga per satuan faktor produksi ke $\mathrm{i}$ 
Pengujian yang dapat dilakukan untuk membuktikan bahwa NPM/Px sama dengan satu yaitu dengan membandingkan hasil dari (MPP-Px/Py)/S $\beta \mathrm{i}$ dengan $\mathrm{t}-$ tabel. Apabila nilai (MPP-Px/Py)/S $\beta$ i lebih besar dari t-tabel, maka pengujian tersebut signifikan artinya NPM/Px tidak sama dengan satu. Sebaliknya bila nilai (MPP-Px/Py)/S $\beta i$ lebih kecil dari t-tabel, maka pengujian tersebut non signifikan artinya NPM/Px sama dengan satu. Nilai $\beta$ i merupakan besarnya koefisien regresi masing-masing faktor produksi dan S $\beta$ i merupakan besarnya simpangan baku koefisien regresi masing-masing faktor produksi.

Penilaian yang digunakan untuk mengukur tingkat efisiensi adalah sebagai berikut (Soekartawi, 1994).

a) Jika rasio NPMxi dengan Pxi lebih kecil dari satu, menunjukan penggunaan faktor produksi telah melampaui batas optimal, maka setiap penambahan biaya akan lebih besar dari tambahan penerimaannya. Pada kondisi ini penggunaan faktor produksi Xi tidak efisien, maka perlu dilakukan pengurangan penggunaan faktor produksi yang dimaksud.

b) Ketika NPMxi sama dengan Pxi atau rasio antara NPMxi dengan Pxi sama dengan satu, menunjukkan bahwa penggunaan faktor produksi telah sesuai. Pada kondisi ini penggunan faktor produksi sudah efisien.

c) Pada saat rasio NPMxi dengan Pxi lebih besar dari satu, menunjukkan bahwa penggunaan faktor produksi belum efisien.Hal ini berarti kondisi optimum belum tercapai, maka perlu dilakukan penambah penggunaan faktor produksi sehingga tercapai kondisi efisien.

\section{Hasil dan Pembahasan}

\subsection{Pengaruh faktor produksi terhadap produksi cabai merah}

Pengaruh faktor produksi terhadap jumlah produksi cabai merah dianalisis dengan melihat hasil uji koefisien determinasi $\left(\mathrm{R}^{2}\right)$, uji ragam regresi, dan uji koefisien regresi yang dijabarkan sebagai berikut.

Tabel 1.

Hasil Uji Koefisien Determinasi $\left(\mathrm{R}^{2}\right)$

\begin{tabular}{ccccc}
\hline Observasi & $\mathrm{R}$ & $\mathrm{R}^{2}$ & $\mathrm{R}^{2}$ terkoreksi & $\begin{array}{c}\text { Std. Error } \\
\text { Estimasi }\end{array}$ \\
\hline 62 & 0,969 & 0,939 & 0,930 & 0,061 \\
\hline
\end{tabular}

Sumber : Data primer diolah (2017)

Nilai $\mathrm{R}^{2}$ model regresi pendugaan produksi cabai merah adalah 0,939 . Hal ini menunjukkan sebesar 93,90\% variasi keragaman total produksi cabai merah dipengaruhi oleh variasi penggunaan faktor produksi yang digunakkan dalam model regresi, sedang sisanya $(6,10 \%)$ dipengaruhi oleh faktor lainnya diluar faktor produksi yang digunakkan dalam model regresi penduga. Nilai koefisien determinasi 
tersebut juga menandakan bahwa model pendugaan regresi yang digunakan sudah cukup baik.

Tabel 2.

Hasil Uji Ragam Regresi

\begin{tabular}{lcrrrrr}
\hline \multicolumn{1}{c}{ Model } & JK & \multicolumn{1}{c}{ DB } & \multicolumn{1}{c}{ KT } & F $_{\text {-hitung }}$ & $\mathrm{F}_{(5 \% ; 10 ; 54)}$ & Signifikansi \\
\hline Regresi & 3,028 & 8 & 0,378 & 101,694 & 2,011 & 0,000 \\
Residual & 0,197 & 51 & 0,004 & & & \\
Total & 3,225 & 61 & & & & \\
\hline
\end{tabular}

Sumber : Analisis Data Primer, 2017

Uji ragam regresi digunakan untuk menunjukkan hubungan atau pengaruh masing-masing penggunaan faktor produksi secara bersama-sama atau simultan terhadap produksi cabai merah. Pada Tabel 2. nilai signifikansi dari uji ragam regresi sebesar 0,000 yang menunjukkan nilai tersebut berada dibawah nilai peluang 0,05 (lima persen), sehingga secara simultan penggunaan faktor produksi luas lahan, benih, pupuk kandang, NPK, pupuk daun, kalsium, pestisida, dan tenaga kerja berpengaruh nyata terhadap produksi cabai merah di Desa Besakih.

Tabel 3.

Hasil Uji Koefisien Regresi

\begin{tabular}{lccc}
\hline \multirow{2}{*}{ Variabel } & Koefisien & t-hitung & \multirow{2}{*}{ Sig. } \\
\cline { 2 - 3 } & $\mathrm{B}$ & Std. Error & \\
\hline (Constant) & 0,812 & 0,325 & $0,015^{* *}$ \\
Luas lahan & 0,114 & 0,057 & $0,051^{\mathrm{N} \mathrm{S}}$ \\
Benih & 0,856 & 0,074 & $0,000^{* *}$ \\
Pupuk Kandang & 0,221 & 0,082 & $0,009^{* *}$ \\
NPK & 0,279 & 0,138 & $0,048^{* *}$ \\
Pupuk Daun & $-0,033$ & 0,041 & $0,433^{\mathrm{N} \mathrm{S}}$ \\
Kalsium & 0,022 & 0,154 & $0,885^{\mathrm{N} \mathrm{S}}$ \\
Pestisida & 0,073 & 0,035 & $0,043^{* *}$ \\
Tenaga Kerja & $-0,026$ & 0,041 & $0,531^{\mathrm{N} \mathrm{S}}$ \\
\hline
\end{tabular}

Keterangan : $* *=$ Signifikan pada taraf beda nyata $\alpha=5 \%$

NS $=$ Non Signifikan

Sumber : Analisis Data Primer, 2017

Berdasarkan Tabel 3. faktor produksi yang mempengaruhi jumlah produksi cabai merah antara lain benih, pupuk kandang, pupuk NPK, dan pestisida, sedangkan untuk faktor luas lahan, pupuk daun, kalsiumdan tenaga kerja tidak berpengaruh terhadap jumlah produksi cabai merah di Desa Besakih. Hal ini dapat dilihat dari nilai signifikan, apabila nila signifikan lebih kecil dari 0,05 maka faktor produksi 
tersebut dikatakan memiliki pengaruh terhadap produksi cabai merah, begitupula sebaliknya.

Berdasarkan uji tersebut juga dapat diperoleh persamaan regresi yang dihasilkan adalah

$$
\begin{aligned}
\log \hat{Y}= & 0,812+0,114 \log \mathrm{X} 1+0,856 \log \mathrm{X} 2+0,221 \log \mathrm{X} 3+ \\
& 0,279 \log \mathrm{X} 4-0,033 \log \mathrm{X} 5+0,022 \log \mathrm{X} 6+ \\
& 0,073 \log \mathrm{X} 7-0,026 \log \mathrm{X} 8 \ldots \ldots \ldots \ldots \ldots \ldots \ldots \ldots \ldots \ldots \ldots \ldots \ldots \ldots \ldots \ldots \ldots \ldots \ldots \ldots \ldots \ldots \ldots \ldots \ldots \ldots
\end{aligned}
$$

\subsection{Efisiensi Penggunaan Faktor Produksi Usahatani Cabai Merah di Desa Besakih}

Efisiensi penggunaan faktor produksi dapat diketahui dengan cara menghitung nilai produksi marjinal masing-masing variabel produksi. Nilai produksi marjinal (NPMxi) dapat diperoleh melalui perbandingan hasil perkalian antara produksi marginal (MPPxi) dan harga jual cabai merah (Py) dengan harga input produksi yang digunakan dalam usahatani cabai merah (Xi). Berikut ini merupakan hasil analisis efisiensi penggunaan faktor produksi usahatani cabai merah di Desa Besakih.

Tabel 4.

Hasil Analisis Penggunaan Faktor Produksi Cabai Merah di Desa Besakih

\begin{tabular}{lrrrrc}
\hline \multicolumn{1}{c}{ Variabel } & \multicolumn{1}{c}{ Px } & NPMxi & $\begin{array}{c}\text { NPM/ } \\
\text { Px }\end{array}$ & Hasil Uji & Keterangan \\
\hline Benih (kg) & $10.822,58$ & $34.591,22$ & 3,20 & Signifikan & Belum Efisien \\
Pupuk kandang (kg) & 279,84 & $3.495,98$ & 12,49 & Signifikan & Belum Efisien \\
Pupuk NPK (kg) & $5.067,74$ & $4.900,37$ & 0,97 & Non Signifikan & Efisien \\
Pupuk Daun (l) & $42.475,81$ & $-1.383,84$ & $-0,03$ & Signifikan & Tidak Efisien \\
Kalsium (kg) & $20.612,90$ & $-16.963,57$ & $-0,82$ & Signifikan & Tidak Efisien \\
Pestisida (l) & $2.742,09$ & $1.319,57$ & 0,48 & Signifikan & Tidak Efisien \\
Tenaga kerja (HOK) & $65.806,45$ & $-947,78$ & $-0,01$ & Signifikan & Tidak Efisien \\
\hline Sumber : Data primer
\end{tabular}

Sumber : Data primer diolah (2017)

Berdasarkan Tabel 4. penggunaan faktor produksi yang sudah efisien adalah NPK. Faktor produksi yang belum efisien antara lain benih dan pupuk kandang, sehingga penggunaannya perlu ditambahkan. Faktor produksi pupuk daun, kalsium, pestisida, dan tenaga kerja tergolong tidak efisien, sehingga perlu dikurangi penggunaannya hingga mencapai efisien.

\section{Simpulan dan Saran}

\subsection{Simpulan}

Faktor-faktor yang mempengaruhi produksi cabai merah di Desa Besakih, Kecamatan Rendang, Kabupaten Karangasem adalah luas lahan, benih, pupuk kandang, NPK, pupuk daun, Kalsium, pestisida, dan tenaga kerja. Secara simultan seluruh faktor produksi berpengaruh nyata terhadap jumlah produksi cabai 
merah.Secara parsial faktor produksi yang mempengaruhi jumlah produksi cabai merah adalah benih, pupuk kandang, NPK, dan pestisida. Penggunaan faktor produksi dalam usahatani cabai merah yang sudah efisien adalah penggunaan NPK . Faktor produksi yang belum efisien adalah benih dan pupuk kandang. Faktor produksi yang tidak efisien adalah pupuk daun, pupuk kalsium, pestisida, dan tenaga kerja.

\subsection{Saran}

Adapun saran yang dapat penulis sampaikan, petani diharapkan mampu menggunakan berbagai faktor produksi petani dengan jumlah yang sesuai agar mencapai efisien.Penggunaan NPK sudah mencapai efisien, sehingga penggunaan NPK tetap dipertahankan. Penggunaan benih dan pupuk kandang perlu ditambahkan jumlah penggunaannya, sedangkan penggunaan pupuk daun, pupuk kalsium, pestisida, dan tenaga kerja perlu dikurangi jumlah penggunaannya.

\section{Ucapan Terima Kasih}

Ucapan terima kasih ini peneliti tujukan kepada seluruh pihak yang telah membantu dalam pelaksanaan penelitian hingga karya ilmiah ini bisa dipublikasikan dalam e-jurnal .

\section{Daftar Pustaka}

Badan Pusat Statistik. 2015. Karangasem dalam Angka 2015. diunduh pada https://karangasemkab.bps.go.id/(diakses pada tanggal 29 November 2016).

Badan Pusat Statistik. 2016. Karangasem dalam Angka 2016. diunduh pada https://karangasemkab.bps.go.id/(diakses pada tanggal 29 November 2016).

Direktorat Jenderal Hortikultura. 2015. diunduh pada Konsumsi Hortikultura 2015. http://hortikultura.pertanian.go.id/ (diakses pada tanggal 31 Desember 2016).

Kurniawan Robert dan Budi Yuniarto. 2016. Analisis Regresi Dasar dan Penerapannya dengan $R$. Kencana: Jakarta.

Santoso Singgih. 2002. Statistik Parametrik. Cetakan Ketiga. PT Gramedia Pustaka Utama: Jakarta.

Santoso, Singgih. 2015. Menguasai Statistik Multivariat. PT Elex Media Komputindo: Jakarta.

Saptana, A. Daryanto, H.K. Daryanto dan Kuntjoro. 2010. Analisis Efisiensi Teknis Produksi Usahatani Cabai Merah Besar Dan Perilaku Petani Dalam Menghadapi Risiko. Jurnal Agro Ekonomi. diunduh pada http://ejurnal.litbang.pertanian.go.id (diakses pada tanggal 20 April 2017)

Sugiyono. 2012.Metode Penelitian Bisnis. Alfabeta: Bandung.

Soekartawi. 1994. Teori Ekonomi Produksi, dengan pokok Bahasan Analisis Fungsi Cobb-Douglas. Rajawali Pers, Jakarta

Tenaya, Narka. 2009. Bahan Kuliah Ekonometrika Program Studi Agribisnis. Laboratorium Statistika Fakultas Pertanian Universitas Udayana: Denpasar. 